\title{
Forensic investigation of Barzanian mass grave skeletal remains at Busaya desert in Samawa, Iraq
}

\begin{abstract}
Background and objective: Human identification and anthropological evaluation of mass graves are the key step towards scientific documentation and achieving justice. This study aimed to investigate the exhumation, anthropological evaluation, and individual victim identification of a mass grave in Busaya in Samawa governorate.

Methods: The investigation included excavation of the graves and identification of the victims. The field study was started after taking testimonies and witnesses for locating the site of graves. The sites were determined, which were excavated according to the scientific standard procedures. Gender determination and age and stature estimation were performed on the remnant skeletons in the laboratory of the medico-legal institute in Erbil.

Results: The grave included 93 bodies, 66 (71\%) were males, 24 (26\%) were possibly males, while the others were not identified because of degradations of the bones. The results of age estimation reported that the number of young bodies under 20 years old were five cases (5.4\%), while 53 cases (57\%) were young bodies between 20-29 years. The rest were more than 30 years old, except for eight cases that could not be identified. The results of stature revealed that more than half of cases had stature more than $166 \mathrm{~cm}$, while only six cases were less than $155 \mathrm{~cm}$. All the remained bones were recorded in detail for more documentation.

Conclusion: These findings described the anthropological evaluation of a large Barzanian mass graves in Busaya desert in the south region in Iraq. The majority (or all) of the victims were males and young people.
\end{abstract}

Keywords: Mass grave; Barzanian victims; Busaya; Exhumation; Identification.

\section{Introduction}

Investigation and identification of mass graves skeletal remnant are the most important steps toward documenting human rights violations and giving back to families the remaining skeleton of victims, which were considered until exhumed, as lost or disappeared. ${ }^{1}$ Mass graves in Iraq are identified as unmarked sites containing at least six bodies. Some can be characterized as deep pits that appeared to have been filled or by mounds of earth piled above the ground. However, older mass graves are difficult to find because they might have been covered by debris and vegetation over this long time. ${ }^{2}$ Various mass graves have been discovered in all
Kurds killed via a process of genocide because of their ethnicity. In 1983 during regions of Iraq that contain people of different religious and ethnic groups in the country as well as foreign nationals, including Arabs such as Kuwaitis and Saudis. $^{3}$ The Iraqi government estimates that there were 250000 to a million missing people, according to the International Commission on Missing Persons (ICMP). However, some estimates put the number of missing from Saddam Hussain's attacks, including attacks against the Kurds in the 1980s and 1990s, at more than one million. Therefore, the Kurdish people often say that "there is another Iraq, buried under Iraq." 4 Iraqi Kurdistan Regional

${ }^{1}$ Medical Research Center, Hawler Medical University, Erbil, I raq

* Correspondence: dr_yka@yahoo.com 
Government reported that many mass graves in Kurdistan region contained Iraqi a military attack against Kurdish citizens in Barzan region, about 8000 individuals belonging to the Barzani tribe were rounded up by the regime in northern Iraq and executed in deserts near Basrah in the south of Iraq. ${ }^{5}$ Another operation against Kurds was in 1988, the Anfal campaign, during which as many as 182,000 Iraqi Kurds disappeared. Most of them were belonging to the Garmian region. The men were separated from their families and were executed in deserts in the west and south-west of Iraq. The remnants of some of their wives and children have also been found in mass graves. ${ }^{6}$ This investigation aimed to present and discuss the exhumation, anthropological evaluation, and individual victim identification of a Barzanian mass grave in Busaya desert, Samawa governorate in the south region of Iraq.

\section{Methods}

\section{Study setting and design}

The current study was designed as a descriptive investigation for the Barzanian mass grave in Busaya. The fieldwork was started in November 2011, which included taking testimonies and witnesses, site description, and excavation. The morgue study was performed in March 2013. The study duration was nine months. Testimonies and Witnesses for Locating the Graves Sites

Despite the emotional influences on the witness's statements, they were still the most important and reliable source of information for the general or specific site location of the two graves. In this study, the witnesses' statements were depended on which they were victims saved from the killing.

\section{Site Description and Assessment}

Before the excavation took place, a preliminary visit to the suspected site was made to map the area to be excavated. Above all, it was ensured that the area had been cleared of surface debris. The graves sites were in Busaya desert, which is located in Samawa governorate.

\section{Excavation}

After identifying the location of the two gravesites, the major dimensions (width, length, and depth) were estimated as closely as possible. The ground's surface was examined to find any important evidence such as bullets, jewelry, personal belongings, or other evidence. The soil was removed and then probed by careful use of picks and shovel and finally, with trowels and brushes. ${ }^{7}$

\section{Osteological Analysis}

The osteological analysis was concerned with determining the identity of a skeleton by estimating its age, gender, and stature. A count of the 'minimum number of individuals' (MNI) was performed as a standard procedure in osteological reports on inhumations to confirm how many individuals were present by the articulated and disarticulated human bones. The $\mathrm{MNI}$ was calculated by counting all long bone ends, and other larger skeletal elements recovered. The $\mathrm{MNI}$ was considered as the largest number of these skeletons. The MNI was mostly lesser than the actual number of skeletons that have been interred on the site. However, it can represent the scientifically proven minimum number of individuals in the graves. ${ }^{8}$ Age was determined using standard aging techniques. ${ }^{9}$ Age estimation relies on the presence of the pelvis and uses different stages of bone development and degeneration in order to calculate the age of an individual. Age is split into two categories: young victims include the ages under 18 years old, and adult victims, which include ages equal or more than 18 years old. Gender determination was carried out using standard osteological techniques, such as those described by Mays ${ }^{10}$ gender assessment of gender in both males and females who relied on the preservation of the skull and the pelvis and could only be carried out once sexual characteristics have developed during late puberty and 
early adulthood. Stature was estimated by applying the formula for the maximum length of femur developed using modern Portuguese samples. ${ }^{11}$

\section{Data Analysis}

Microsoft Excel program was applied for summarizing and graphical presentation of the data. Percent values were calculated as a descriptive statistical analysis for the acquired data.
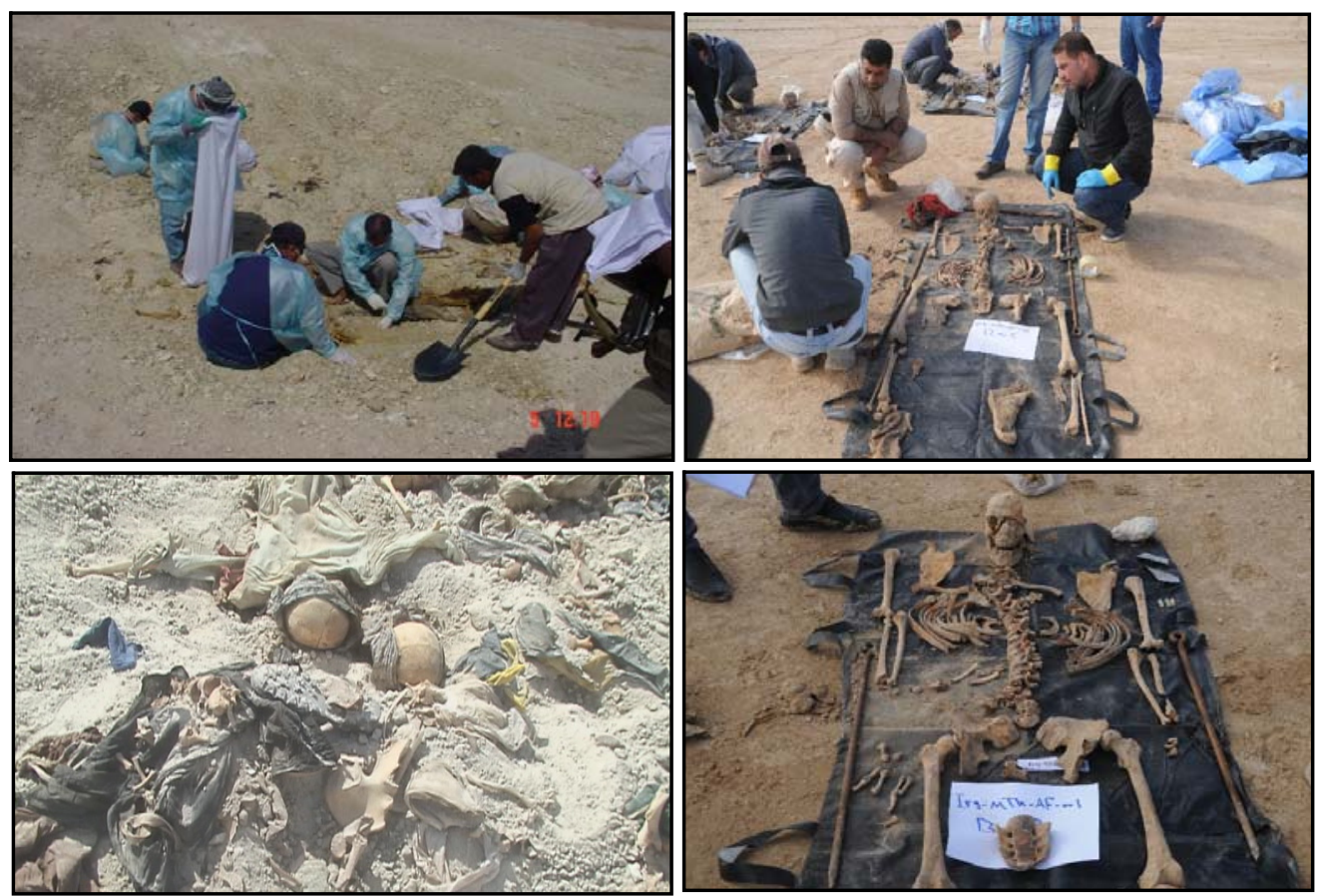

Figure 1: The process of exhumation and bone collection of the mass grave in Busaya desert.

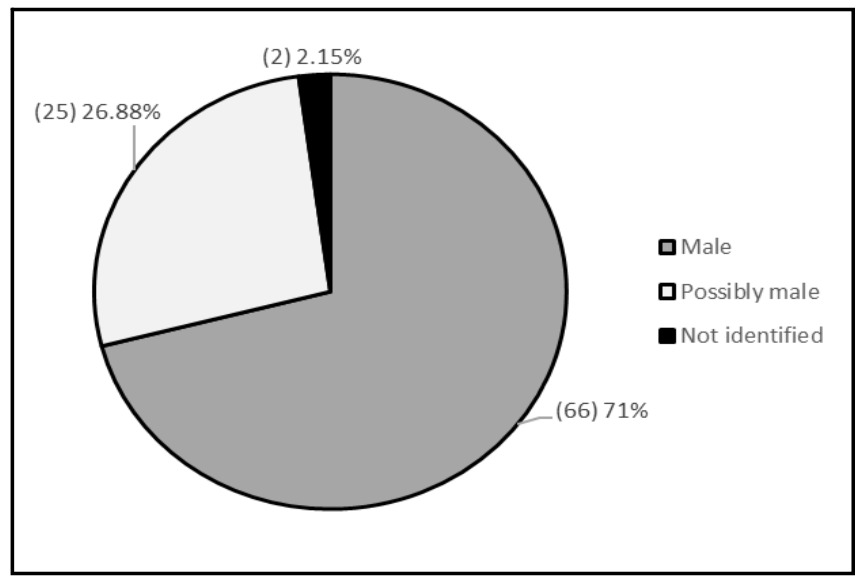

Figure 2: Gender distribution according to gender determination procedure in the mass grave. 
Figure 3 illustrates the distribution of ages of the site. Most of the victims in the mass grave were young people. The number of young bodies between 20-29 years and 30-39 years was 53 (56.99\%) and $19(20.43 \%)$, respectively. Only 5 (5.38\%) out of 93 were less than 20 years of all victims, whereas eight cases were more than 30 years, and eight cases could not be identified because of degradations of the bones. The stature of the victims was estimated according to their ages. The most prominent statures were around $160-170 \mathrm{~cm}$, which was the expected result according to the evidence and testimonies (Figure 4).

\section{Discussion}

Using a special form prepared by ICMP, the present and absent bones for each body were recorded as much as possible. This work was very difficult and needed too much hard work as most of the bones were degenerated. For the determination of gender, we tried to determine all, but some of the bodies were not appropriated for that determination. Most of the victims were males because the operation was to eliminate the Barzani clan, which had produced Kurdish leaders since the 1930s. They had been relocated to southern Iraq in 1975, but in the 1980s, Saddam's

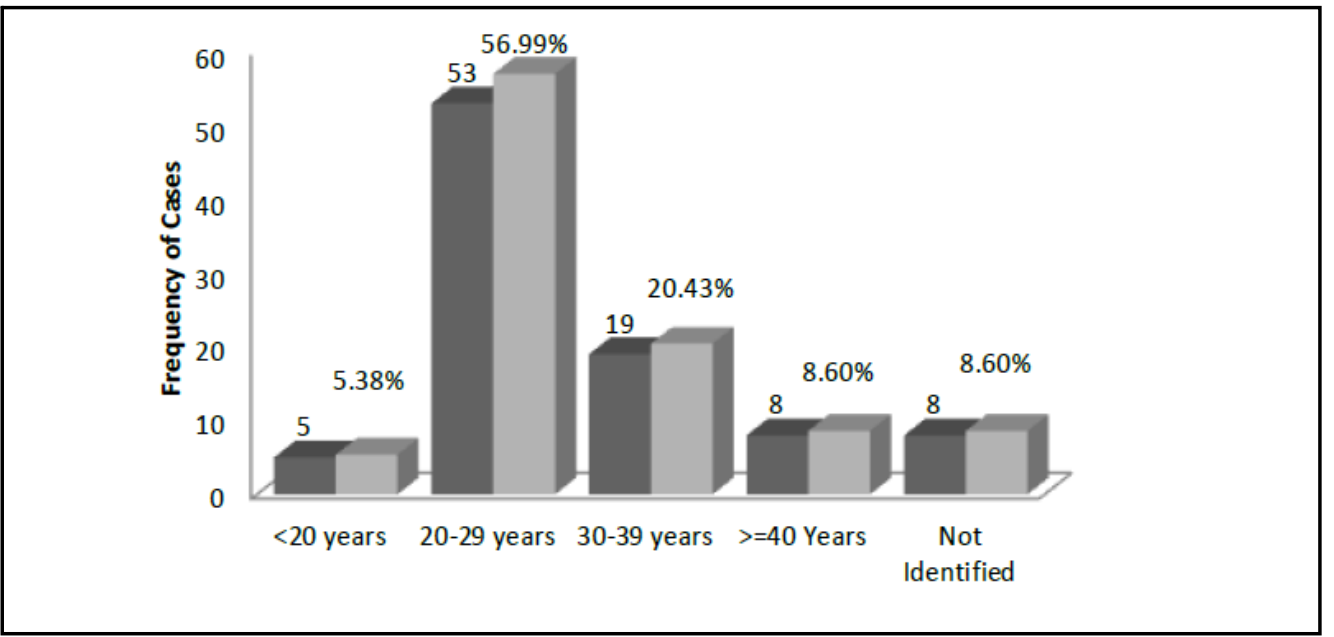

Figure 3: Age distribution according to age determination procedure in the mass grave.

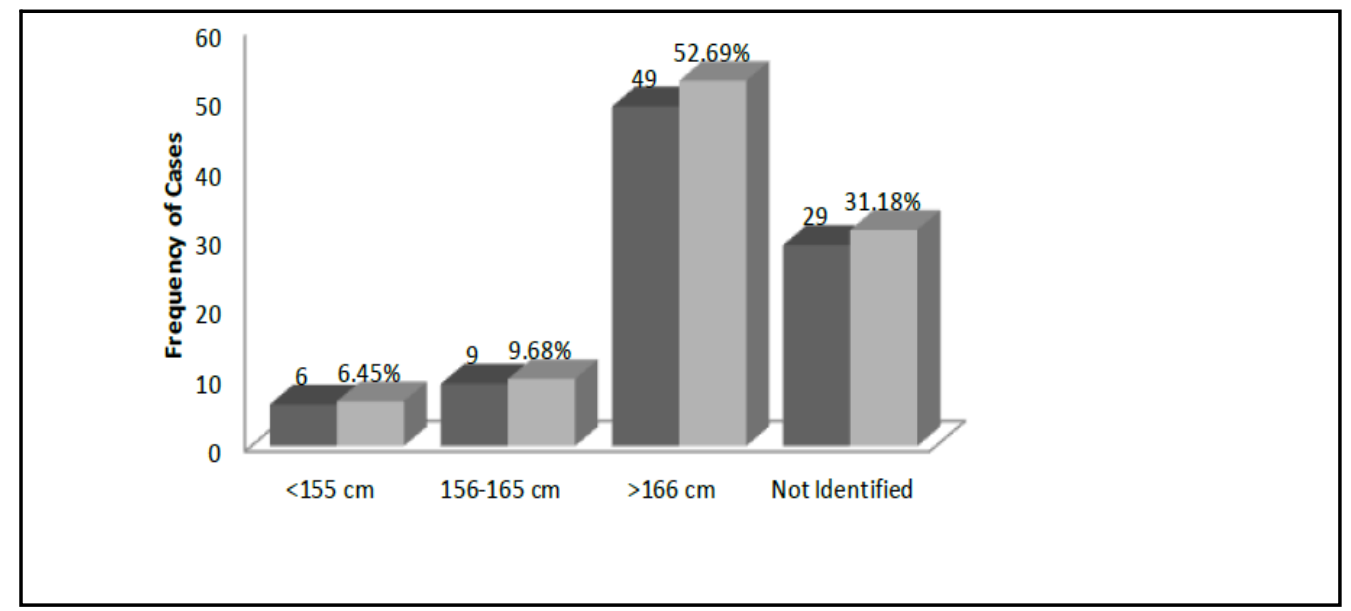

Figure 4: Stature distribution according to age determination procedure in the mass grave. 
soldiers arrested up to 8,000 Barzani males and executed them in mass graves in the south region of $\mid \mathrm{raq} .{ }^{12}$ Despite the usefulness of the technique applied for age identification, the skeletal remnant was the challenge for age determination because the victims' remnant bones determine the efficacy of the results. ${ }^{13}$ Therefore, some cases could not be identified because of the degradations of the bones.

\section{Conclusion}

The current investigation presented the anthropological identification for the victims in a mass grave in Busaya desert. The pieces of evidence confirmed that the mass grave belonged to the Barzanian male victims arrested by Saddam's army in the 1980s. Almost all victims were males, and their ages were estimated to be in a range of 20 to more than 40 years.

\section{Competing interests}

The author declares no competing interests.

\section{References}

1. Groen W, Márquez-Grant N, Janaway R. Forensic archaeology: a global perspective. London: John Wiley \& Sons; 2015.

2. Juhl K. The contribution by (forensic) archaeologists to human rights investigations of mass graves: Museum of archaeology, Norway, Stavanger; 2005.

3. Stover E, Haglund WD, Samuels M. Exhumation of mass graves in Iraq: considerations for forensic investigations, humanitarian needs, and the demands of justice. JAMA 2003; 290(5): 663-6.

4. State UDo. Iraq human rights report. In. USA: US State Government; 2015.

5. Congram D, Sterenberg J. Handbook of forensic anthropology and archaeology. California: Left coast Press; 2009. P. 441-53.

6. Black G. Genocide in Iraq: The Anfal campaign against the Kurds: Human Rights Watch; 1993.

7. Schmitt S. Mass Graves and the Collection of Forensic Evidence: Genocide, War. Advances in Forensic Taphonomy: Method, theory, and archaeological perspectives. Boca Raton, Fla.: CRC Press; 2002. P. 277-92.

8. McKinley Jl. Compiling a skeletal inventory: cremated human bone. Updated Guidelines to the Standards for Recording Human Remains. UK, Chartered Institute for Archeologists; 2004. P. 54-7.
9. Cox M. Ageing adults from the skeleton. Human osteology in archaeology and forensic science. UK: Cambridge University Press; 2000. P. 6182.

10. Mays S. Sex determination in skeletal remains. Human Osteology in Archeology and Forensic Science. UK: Cambridge University Press; 2000. P. 117-30.

11. De Mendonca M. Estimation of height from the length of long bones in a Portuguese adult population. Am J Phys Anthropol 2000; 112(1): 39-48.

12. Byman DL. Divided they stand lessons about partition from Iraq and Lebanon. Security Studies 1997; 7(1):1-29.

13. Komar DA, Buikstra JE. Forensic anthropology: contemporary theory and practice. New York: Oxford University Press; 2008. 